UJMR, Volume 6 Number 1, June, 2021, pp 56-61 ISSN: 2616 - 0668

https://doi.org/10.47430/ujmr.2161.007

Received: $17^{\text {th }}$ Feb, 2021

Accepted: $11^{\text {th }}$ Mar, 2021

\title{
Bacterial Contaminants Associated with the Hands of Food Handlers at Ahmadu Bello University, Zaria
}

\author{
${ }^{* 1}$ Jimoh, O., ${ }^{2}$ Abdulkadir, M.I., ${ }^{2}$ Yusuf, T. I., ${ }^{2}$ Mohammed, B. I., ${ }^{3}$ Ige, O.T., ${ }^{1}$ Ibrahim, \\ M. , ${ }^{1}$ Oriya,A., ${ }^{1}$ Yusuf S., ${ }^{1}$ Idris M.S. and ${ }^{4}$ Ahmed S.A \\ ${ }^{1}$ Department of Medical Microbiology, Ahmadu Bello University, Zaria- Nigeria \\ ${ }^{2}$ University Medical Centre, Ahmadu Bello University, Zaria - Nigeria \\ ${ }^{3}$ Department of Medical Microbiology and Parasitology, Kaduna State, University, Kaduna - \\ Nigeria \\ ${ }^{4}$ Department of Pathology, Ahmadu Bello University, Zaria-Nigeria/Federal Medical \\ Centre, Abuja \\ Corresponding Author: drwritelanrej@yahoo.com; +2347038505938
}

\begin{abstract}
Food and water borne diseases are leading cause of morbidity and mortality in developing countries. This study identified bacterial agents contaminating the hands of food handlers at Ahmadu Bello University Zaria. A total of 205 food handlers were recruited, their hands were swabbed, processed to isolate and identify bacteria using standard microbiological techniques. Of the two hundred and five (205) participants, fifty-five (55) were positive for bacterial contamination (26.8\%). Fifty-nine (59) different bacteria strains were isolated; Staphylococcus aureus was the commonest with the frequency of $29(49 \%)$. Other foodborne pathogens isolated were Escherichia coli $4(6.8 \%)$ and Salmonella subspecies IIIb 1(1.7\%). It has been shown from this study that a significant proportion of food handlers' hands were contaminated with bacterial agents. Therefore, optimizing hand hygiene programme among food handlers will help to minimize food contamination.

Keywords: Hygiene, Food, contamination, Bacteria
\end{abstract}

\section{INTRODUCTION}

Food is the basic necessity of human life. For a healthy life, it is not only important to eat food but to eat quality and hygienic food. A food handler is a person who is directly involved in, cooking, serving food, touching food equipment and utensils or food environment or contact surfaces(Ifeadike et al., 2014; Mohtaram et al., 2017). For safe food consumption devoid of any form of contamination, a food handler must adhere strictly to proper hand and other food hygiene practices(Mushtaq, 2018).

The World Health Organization (WHO) estimated that up to $70 \%$ of the populations suffer from diarrheal diseases in developing countries, with an estimated 2 million deaths per year. These diseases are caused mostly by food-borne pathogens such as Staphylococcus aureus, Salmonella spp, Escherichia coli, Shigella, and other related intestinal parasites(Bafa et al., 2019). Food and waterborne diarrheal diseases are leading causes of morbidity and mortality in developing countries accounting for an estimated 2.2 million death of adults and 3million children annually(Oladoyinbo et al., 2015; WHO, 2015). Food-borne diseases do not only affect people's health and well-being but have economic consequences for individuals, families, communities, businesses, and countries(Omoleke,2015; Umar et al., 2018). Food may be contaminated by some pathogenic organisms such as Salmonella species, Escherichia coli,Campylobacter species, helminths and protozoa through contaminated hands(Lambrechts,2014). Chronic asymptomatic carriers of Salmonella species perpetuate typhoid fever in the human-environment by intermittently shedding the organism into the environment and spread do occur faeco-orally (Gunn, 2014). Food vendors and processors may be important vehicles of infection transmission. Staphylococcal food poisoning is a global challenge due to food-borne pathogens, affected individuals that developed diarrhea which may be severe if early treatment is not instituted(Humodi et al.,2010; Kadariya et al. ,2014). 
Unhygienic food handlers remain the source of most reported food-borne outbreaks (Fiore, 2004; Asgharet al., 2006).

Microbial transmission occurs through food, water, nails, and fingers that are contaminated with faeces (Havelaar et al., 2015). Food handlers that are chronic carriers and excrete bacteria may contaminate foods. Beneath the fingernail is a habitat for spreading pathogenic bacteria because it is an area where people hardly concentrate when performing hand hygiene (Mengist et al., 2018).

Although, in Ahmadu Bello University food handlers are screenedyearly for some foodborne pathogens, published research on the risk factors and bacterial contamination associated with the food handler's hand are scarce. This research aimed to contribute to the existing scarce informationon bacterial contaminants associated with the hands of food handlers at Ahmadu Bello University, Zariawith the hope of promoting adequate and effective hand hygiene practices among food handlers in tertiary educational institutions.

\section{MATERIALS AND METHODS}

\section{Study area}

The study was conducted at Ahmadu Bello University Zaria, a tertiary educational institution in Northwestern Nigeria. The University is cosmopolitan that accommodates students from within and outside Nigeria. Its environment comprises different food vendors from different ethnic groups in Nigeria.

\section{Data collection}

A structured interviewer-administered questionnaire was used to obtain demographic details (age, sex, marital status, educational status, and duration of food handling time).

Specimens collection and processing

Palms and fingers of participants were swabbed with sterile swab stick that was moistened with sterile saline into the sterile container as inoculation was done within 1 hour of collection Bacteria Isolation and identification

The collected swabs were separately streaked on the prepared blood and McConkey agar plates and incubated at $37^{\circ} \mathrm{C}$ for 24 hours. Bacteria isolates were characterized using the colonies morphology, biochemical tests and gram staining technique. Gram-negative rods were identified by performing a series of biochemical tests such as Triple sugar iron agar (TSI), Urea, Citrate, Oxidase, and motility. Gram-positive cocci were also identified based on their Gram reaction, catalase, and coagulase test results. Commercially available API Microbactkit (Oxoid) were used to further specify gram-negative bacilli.

Data analysis and Patient Confidentiality

Personal identifiers were removed from the study files that are accessible to non-study personnel. Data analysis was done using Statistical Package for Social Science version 20. Univariate and bivariate analyses were conducted. The chi-square, Fisher's exact test were used to assess the unadjusted significance of associations between categorical variables. A p-value of 0.05 or less was considered statistically significant

\section{RESULTS}

Total of 205 food handlers with the mean age of $35.8 \pm 13.9$ years, and an age range of 17 72years participated in the study. The majority of the participants, 166(81\%) were female, while $104(50.7 \%)$ were within age group 26 50years. Larger proportion of $106(51.7 \%)$ were married with $26 \%$ among them without any formal education. Of these participants, a significant proportion of $99(48.3 \%)$ were Hausa ethnic groups followed by a combination of other minority ethnic groups (Table 1).

The majority of the participants $162(79 \%)$ were working as permanent staff/owners of the food outlet. Total of $69(33.7 \%)$ participants were working for a period of 1-5years while only $29(14.1 \%)$ have been working for 10years and above. Majority of the participants (189 "92.2 $\%$ ") used pipe-borne water for cooking while $136(66.3 \%)$ of them use water closet as their toilet facility. Commonest vegetable consumed/handled by $68(33.2 \%)$ participants was carrot.Majority 199(97.1\%) washes the carrot before being handled/consumed and also $184(89.8 \%)$ wash their hands before serving the food. About 153(74.6) knew that typhoid and cholera 171(83.4) can be transmitted through food while 105(51.2) knew hepatitis $A$ and $E$ as food-borne infection. The majority of the participants $152(74.1 \%)$ had previous training on food hygiene and $175(85.4)$ of them are still interested in having retraining (Table 2 ).

Of the 205 total participants, 55 were positive for bacterial contamination representing $26.8 \%$. A total of 59 bacteria strains were isolated from those 55 participants. Staphylococcus aureus a gram-positive bacterium was the commonest organism isolated $29(49 \%)$. Other important bacteria isolates were Escherichia coli 4(6.8) and Salmonella subspecie1 "1.7\%" (Table 3). 
Of all the factors examined, statistically washing vegetable before consumption, significant association was observed between, facemask usage during food preparation and age of the participants, types of vegetable, bacterial contamination $(p<0.05)$.

Table1: Socio-demographic characteristics of food handlers at Ahmadu Bello University Zaria

\begin{tabular}{lll}
\hline Variable & Frequency $\mathbf{n = ( 2 0 5 )}$ & Percentage (\%) \\
\hline Sex & 39 & \\
Male & 166 & 19.0 \\
Female & & 81.0 \\
Age & 67 & 32.7 \\
$<25$ & 104 & 50.7 \\
$\mathbf{2 6 - 5 0}$ & 34 & 16.6 \\
$\mathbf{5 1 - 7 5}$ & & \\
Marital status & 69 & 33.7 \\
Single & 106 & 51.7 \\
Married & 30 & 14.6 \\
Divorced & & \\
Educational status & 44 & 21.5 \\
Primary & 79 & 38.5 \\
Secondary & 28 & 13.7 \\
Tertiary & 54 & 26.3 \\
Others/none & & \\
Ethnicity & 99 & 48.3 \\
Hausa & 22 & 0.7 \\
Fulani & 13 & 6.3 \\
Yoruba & 6 & 2.9 \\
Igbo & 65 & 31.7 \\
Others & & \\
\hline
\end{tabular}

Table 2: Associated risk factors for food handlers at Ahmadu Bello University Zaria

\begin{tabular}{lll}
\hline Risk factors & Frequency & Percentage (\%) \\
\hline Occupation/Staffing & 162 & 79.0 \\
Permanent & 43 & 21.0 \\
Casual & 65 & 31.7 \\
Working experience(year) & 69 & 33.7 \\
$<1$ & 42 & 20.5 \\
$1-5$ & 29 & 14.1 \\
$6-10$ & 189 & 92.2 \\
$>10$ & 2 & 1.0 \\
Water sources & 6 & 2.9 \\
Tap water & 8 & 3.9 \\
River/stream water & & \\
Well water & 136 & 66.3 \\
Others & 61 & 29.8 \\
Type of toilet & 2 & 1.0 \\
Water closet & 6 & 2.9 \\
Pit latrine & & \\
Bush & 199 & 97.1 \\
Others & 6 & 2.9 \\
Washing of vegetable before consumption & \\
Yes & & \\
No & 68 & \\
Types of vegetables & 65 & \\
Carrot & 42 & \\
Cabbage & 27 & 89.8 \\
Lettuce & 3 & 10.2 \\
Tomatoes & & 30.7 \\
Others & & \\
Washing of hands before serving food & & 69.3 \\
Yes & 184 & \\
No & 21 & \\
Wearing a face mask when serving & & \\
Yes & 63 & \\
No & 142 & \\
\hline
\end{tabular}


UJMR, Volume 6 Number 1, June, 2021, pp 56-61 ISSN: 2616 - 0668

Table 3: Bacteria isolated from food handlers at Ahmadu Bello University Zaria

\begin{tabular}{lll}
\hline Bacteria isolates & Frequency & Percentage \\
\hline Acinetobacter baummannii & 3 & 5.1 \\
Acinetobacter iwoffii & 7 & 11.9 \\
Acinetobacter haemolyticus & 1 & 1.7 \\
Citrobacter sakarzakii & 1 & 1.7 \\
E. agglomerans & 1 & 1.7 \\
Enterobacter cloacae & 2 & 3.4 \\
Escherichia coli & 4 & 6.8 \\
E. gergoviae & 1 & 1.7 \\
K. pneumonia & 5 & 8.5 \\
Klebsiellae ozoanae & 1 & 1.7 \\
Morganella morganii & 2 & 3.4 \\
Pseudomonas aeruginosa & 1 & 1.7 \\
S. aureus & 29 & 49.0 \\
Salmonella subspecies IIIb & 1 & 1.7 \\
Total & 59 & 100 \\
\hline
\end{tabular}

TABLE 4: Hand Contamination and Associated risk factors among the food handlers at Ahmadu Bello University Zaria

\begin{tabular}{|c|c|c|c|}
\hline \multirow[t]{2}{*}{ Risk Factors } & \multicolumn{2}{|c|}{ Hands Contamination } & \multirow[t]{2}{*}{ P-value } \\
\hline & Presence & Absence & \\
\hline \multicolumn{4}{|l|}{ Age(years) } \\
\hline$\leq 25$ & $11(16.4)$ & $56(83.66)$ & $0.011^{*}$ \\
\hline $26-50$ & $29(27.9)$ & $75(72.1)$ & \\
\hline $51-75$ & $15(44.1)$ & $19(55.9)$ & \\
\hline \multicolumn{4}{|c|}{ Working Experience } \\
\hline$<1$ Year & $21(32.3)$ & $44(67.7)$ & 0.17 \\
\hline 1-5 Years & $12(17.4)$ & $57(82.6)$ & \\
\hline 6-10 Years & $12(28.6)$ & $30(71.4)$ & \\
\hline$>10$ Years & $55(26.8)$ & $150(73.2)$ & \\
\hline \multicolumn{4}{|c|}{ Educational Level } \\
\hline Primary & $15(34.1)$ & $29(65.9)$ & 0.09 \\
\hline Secondary & $17(21.5)$ & $62(78.5)$ & \\
\hline Tertiary & $4(14.3)$ & $24(85.7)$ & \\
\hline Others & $19(35.2)$ & $35(64.8)$ & \\
\hline \multicolumn{4}{|c|}{ Types of Vegetable } \\
\hline Carrot & $22(32.4)$ & $46(67.6)$ & $0.03^{*}$ \\
\hline Cabbage & $13(20.0)$ & $52(80.0)$ & \\
\hline Lettuce & $11(26.2)$ & $31(73.8)$ & \\
\hline Tomatoes & $6(22.2)$ & $21(77.8)$ & \\
\hline Others & $3(100.0)$ & $0(0.0)$ & \\
\hline \multicolumn{4}{|c|}{$\begin{array}{l}\text { Washing Vegetable Before } \\
\text { Consumption }\end{array}$} \\
\hline Yes & $51(25.6)$ & $148(74.4)$ & $0.02^{*}$ \\
\hline No & $4(80.0)$ & $1(20.0)$ & \\
\hline Others & $0(0.0)$ & $1(100)$ & \\
\hline \multicolumn{4}{|c|}{$\begin{array}{l}\text { Washing Hands Before Serving } \\
\text { Food }\end{array}$} \\
\hline Yes & $48(26.1)$ & $136(73.9)$ & 0.48 \\
\hline No & $7(33.3)$ & $14(66.7)$ & \\
\hline \multicolumn{4}{|c|}{$\begin{array}{l}\text { Face Mask Usage During } \\
\text { Preparation of Food }\end{array}$} \\
\hline Yes & $10(16.1)$ & $52(83.9)$ & $0.02^{*}$ \\
\hline No & $45(31.5)$ & $98(68.5)$ & \\
\hline \multicolumn{4}{|c|}{$\begin{array}{l}\text { Face Mask usage when Serving } \\
\text { Food }\end{array}$} \\
\hline Yes & $9(14.3)$ & $54(85.7)$ & $0.01^{*}$ \\
\hline No & $46(32.4)$ & $96(67.6)$ & \\
\hline \multicolumn{4}{|c|}{$\begin{array}{l}\text { Typhoid being feco-orally } \\
\text { transmitted }\end{array}$} \\
\hline Yes & $32(22.9)$ & $118(77.1)$ & $0.03^{*}$ \\
\hline
\end{tabular}

UMYU Journal of Microbiology Research 


\section{UJMR, Volume 6 Number 1, June, 2021, pp 56-61 ISSN: 2616 - 0668}

\section{DISCUSSION}

Food borne pathogens remained the leading cause of food borne diseases due to poor and faulty food handling and preparation processes (Clayton et al.,2002; Ifeadike et al., 2014). Food handlers are potential risk to the public health through microbial transmission (Fawziet al., 2009).In this present research, the overall rate of palm of food handler's bacterial contamination was high $55(26.8 \%)$. However, it was lower than the findings of Jibrin et al. (2016) and Sylvia et al. (2015) who found 89\% and $48 \%$ respectively. The work of Jibrin was done among food handlers in Kano city while that of Sylvia was done in managed food service in Uganda. In another similar research done among university cafeteria food handlers in Egypt by Assefaet al. (2015) a higher contamination rate of $49.6 \%$ in contrast to ours was also observed. The reason for this was because hand of the participants were rinse into a sterile polythene bag from where a loopful was inoculated into the culture media in comparison to this current research where sterile cotton wool swab was used for sample collection. Furthermore a significant proportion $(74.7 \%)$ of food handlers that participate in this work have some form of formal education which might have accounted for the lower level of contamination which is agreement findings reported by Abeba et al., 2018 in Ethiopia. Prabhu and Shah, (2014) reported that food handlers could pose a potential risk to food safety due to low level of education and hence may have little or no knowledge of the risk of microbial or chemical contamination of food or how to get rid of them. Overall findings have demonstrated poor hygiene practice by most of the food handlers working at Ahmadu Bello University Zaria.

Staphylococcus aureus was observed to be the most prevalent bacteria isolated from the swabbed hand of food handler's, this is not as surprising as it is an important widely reported cause of food poisoning globally (Argudin et al.,2010;Lima et al., 2013; Kadariya et al.,2014). This our finding is in agreement with previous $65.4 \%$ Staphylococcus aureus reported by Mohtaram et al., 2017 and with the finding of $71.8 \%$ by Humodi and Hatim, (2010) from Iran and Sudan respectively both reported $S$. aureusas the most common pathogen isolated from food handlers. High contamination rate observed here could be due to the fact that S.aureus as a pathogenic organism is also known as an important commensal of skin and mucous membrane of human. Nearly $50 \%$ healthy human may harbor it as a normal flora in their nasal cavity (Mohtaram et al., 2017) therefore, healthy food handler may contaminate their hand or food environment when sneeze or cough directly on their hand or palm without adhering to proper hand hygiene. Food handler can easily contaminate food with S. aureus during food processing and serving causing food poisoning and attendant consequences on the sufferer.

Moreover, enteric pathogens such as Escherichia coli, Klebsiella species, Enterobacterspeciesand other environmentally colonized Gram negative bacteria Acinetobacterspecies were also isolated from the food handlers that participated in this research. Escherichia coli is a normal commensal in the gastrointestinal tract of human though some strains such as Enteropathogenic, Enterohaemorrhagic, EnterotoxigenicEscherichia coli may cause acute diarrhea disease under certain condition in man (Lambrechts et al.,2014). However, it is not normally found in the hands, and the presence of Escherichia coli gives an indication of recent fecal contamination with enteric bacteria. Escherichia coli is considered one of the enteric pathogens capable of being transmitted by food handlers if hand hygiene is inadequate (Mengist et al., 2018).

Salmonellasub-specie $3 \mathrm{~b}$ isolated from one of the food handlers' hand showed that hand hygiene practice was grossly inadequate, as it is known that Salmonellae specie, is always pathogenic anytime it is isolated from human body. The organism could have colonized the participant's hand following inappropriate hand hygiene after visiting toilet and this has ability to cause outbreak of salmonellosis among students, lecturers and university community.

Age was found to have a direct statistically significant association $(p=0.01)$ with rate of bacterial contamination of food handlers' hand. This may be because as people are getting older they tend to have some ailments which may affect their urine and fecal continence and due to low energy they may not ensure adequate hand hygiene. Nevertheless, the result showed no statistically significant relationship between the duration of service and microbial contamination $(\mathrm{p}=0.2)$.

The result shows that only $63(30.7 \%)$ of the participants wear face mask during food preparation whereas vast majority do not wear. Microbial contamination was found to be higher among the food handlers who do not wear mask during food preparation. Furthermore, our result showed statistically significant association between wearing of face mask and microbial contamination $(p=0.01)$. This might be due to the fact that nasal cavity may be 
colonized with bacteria such Staphylococcus aureus that can be contaminate hands, plates and serving utensils during coughing or sneezing. Hence, wearing face mask has ability to minimized contamination with nasal secretion and saliva.Consumption and washing of vegetables among the study participant was found to be statistically significant ( $p=0.02$ ). This might be as a result of their education level and food safety and hygiene practices among the study participants.

\section{CONCLUSION}

The finding revealed that $26.8 \%$ of food handlers' hands were colonized with bacterial pathogens such as Staphylococcus aureus, Escherichia coli and Salmonella subspecies IIIb which are capable of causing food and water

\section{REFERENCES}

Abeba, M., Getachew, M. and Alemayehu, R. (2018).Prevalence and antimicrobial susceptibility pattern of Salmonella and Shigella among food handlers in catering establishments at DebreMarkos University, Northwest Ethiopia. International Journal of Infectious Diseases, (75):74-79.

Argudín, M. A., Mendoza, M. C. andRodicio, M., R. (2010).Food Poisoning and Staphylococcus aureus Enterotoxins. Toxins (2): 1751-1773

Asghar, A., Zafar, T. and Momenah, A. (2006).Bacteriological and serological survey of infectious diseases among food handlers in Makkah.Ann of Saudi Medicine, 26(2):141-144

Assefa,T., Tasew, H., Wondafrash, B.and Beker, J. (2015). Assessment of Bacterial Hand Contamination and Associated Factors among FoodHandlers Working in the Student Cafeterias of Jimma University Main Campus, Jimma, South West Ethiopia.Journal ofCommunity Medicine and Health education,(5): 345. doi:10.4172/21610711.1000345

Bafa, T. A., Sherif, E. M., Hantalo, A. H., and Woldeamanuel, G.G. (2019). Magnitude of enteropathogens and associated factors among apparently healthy food handlers at Wolkite University Student's Cafeteria, Southern Ethiopia.Biomedical centre of research. Notes, (12):567

Clayton, D. A., Griffith, D. J., Price, P. and Peters, A. C. (2002) Food handlers' beliefs and self?reported practices. borne disease. Our findings emphasized the role of food handlers' hand as a vehicle of foodborne bacterial pathogens transmission that could be a major source of food-borne disease outbreak in the institution. We hereby advocate for proper education and promotion of effective hand hygiene among food handlers in our educational institutions canteens and restaurants.

\section{ACKNOWLEDGEMENT}

We wish to appreciate the members of staff of laboratory unit of University Medical Centre, Department of Medical Microbiology, Ahmadu Bello University Teaching Hospital Zaria Nigeria and all the food handlers that participated in the study.

Conflict of Interest:

There are no conflicts of interest

International Journal of Environmental Health Research, (12):25039.

Fawzi, M., Gomaa, N. F. and Bakr, W. M. K. (2009).Assessment of handwashing facilities, personal hygiene, and the bacteriological quality of hand washers in some grocery and dairy shops in Alexandria, Egypt.Journal of public health association, (1 and 2): 72-93.

Fiore, A. (2004). Hepatitis transmitted by food. Clinical Infectious Disease, 38:705-71530.

Gunn, J. S., Marshall, J. M., Baker, S., Dongol, S., Charles, R. C., Ryan, E., T. (2014). Salmonella chronic carriage: epidemiology, diagnosis, and gallbladder persistence. Trends Microbiology, 22(11): 648-655

Havelaar, A. H., Kirk, M. D., Torgerson, P. R., Gibb, H. J., Hald, T., Lake, R. J. (2015). World Health Organization Global Estimates and Regional Comparisons of the Burden of Foodborne Disease in 2010.PLoS Medicine, 12(12): e1001923. doi:10.1371/Journal of public medicine 1001923

Humodi, A. S. and Hatim, H.H. (2010).Bacteriological and parasitological Assessment of food handlers in the Omdurman area of Sudan.Journal of Microbiology and Immunology of infection, (1):70-73

Ifeadike, C.O., Ironkwe, O. C., Adogu, P. O. U. and Nnebue, C.C. (2014).Assessment of food hygiene practices of food handlers in the Federal capital territory of Nigeria. Tropical Journal of Medical Research, 17(1):10-5. 
Jibrin, Y., Dahiru, F., Aliyu, A., Hamza, I. and Saratu, A., A.(2016). Microbial Contamination of Food Handlers at Various Restaurants in Kano State Metropolis, Kano Nigeria. International Journal of Current Microbiology and Applied Sciences, 5( 5): 165-170

Kadariya, J., Smith, T. C., and Thapaliya, D. (2014). Staphylococcus aureus and staphylococcal food-borne disease: an ongoing challenge in public health. Biomedical research international, 827965. https://doi.org/10.1155/2014/827965

Lambrechts, A. A., Human, I. S., Doughari, J. H. and Lues, J. F. R. (2014). Bacterial contamination of the hands of food handlers as an indicator of hand washing efficacy in some convenient food industries Pak. Journal of Medical Sciences, 30(4):755-758.

Lima, G. C., Loiko, M. R., Casarin, L. S. and Tondo, E. C. (2013). Assessing the epidemiological data of Staphylococcus aureus food poisoning occurred in the State of Rio Grande do Sul, Southern Brazil. Brazilian journal of microbiology, 44(3): 759-763. https: / / doi.org/10.1590/S151783822013005000063

Mengist, A., Aschale, Y. and Reta, A. (2018). Bacterial and Parasitic Assessment from Fingernails in DebreMarkos, Northwest Ethiopia. Canadian Journal of Infectious Diseases and Medical Microbiology Article, ID 6532014, 7 pages https://doi.org/10.1155/2018/6532014

Mohtaram, N., Siavash, M., Soudoh, K., Maryam, S. and Masoumeh, N. (2017). Bacteria assessment of food handlers in
Sari city, Mazandaran province, North of Iran. Journal of infection and public health, 10:171-176

Mushtaq, A. K.(2018). Detection of colonozed pathogenic bacteria from FoodHandlers in Saudi Arabia. Journal of pure and applied microbiology, 12(13):1301-1306

Oladoyinbo, C. A. Akinbule, 0.0. and Awosika, I. A. (2015). Knowledge of food-borne infection and food safety practices among local food handlers in ljebu-Ode Local Government Area of Ogun State. Journal of Public Health Epidemiology, 7(9): 268-273

Omoleke, I. I. (2015). Contemporary issues and challenges of the health sector in Nigeria. Research Journal of Health Sciences. 5(4):210-216

Prabhu, P. M., Shah, R. S. (2014). A study of food handlers in public food establishments in Maharashtra, India, International Journal of Science and Research, 3(7):1485-1489.

Sylvia, A. B., Rose, A. M., John, B.K. (2015). Hygiene practice and food contamination in managed food services facilities in Uganda. African Journal of Food Science, 9(1): 31-42

Umar, A. A., Sambo, M. N., Sabitu, K., Iliyasu, Z., Sufiyanu, M. B. and Hamza, K. L, (2018). Personal and food hygiene practices among street food vendors in Sabongari local government area of Kaduna State, Nigeria.Archives ofMedineand Surgery, 3:77-83

WHO,(2015). Estimatingtheburdenoffoodbornedi seases.https://www.who.int/activities lestimating-the-burden-of-foodbornediseases.ACCESSED 18/2/2020 